\title{
Environmental justice in the therapeutic inner city
}

\begin{abstract}
Vancouver's Downtown Eastside (DTES) has long been characterized as Canada's skid row within public narratives that raise concerns about communicable diseases, open drug use, survival sex work, and homelessness. This stigmatizing gaze has bolstered a deficit-oriented philosophy that emphasizes measures to mitigate these threats, ostensibly by erasing the moral and environmental depravity from the landscape. However, such measures threaten to further marginalize DTES residents by perpetuating public sentiments of fear and disgust toward the inner city. In this paper, we challenge this orientation by reporting the results of a research process in which DTES residents chronicled their impressions of the neighbourhood. Our findings reveal a paradoxical therapeutic response to environmental injustice in the inner city, one that enables society's most marginalized people to find support, solidarity, and acceptance in their everyday struggles to survive, even thrive, amidst the structural and physical violence of the urban margins.
\end{abstract}

Keywords: Therapeutic landscape; environmental justice; Downtown Eastside; Vancouver; Canada 
"Social justice is a matter of life and death"

WHO (2008)

\section{Introduction}

With the world's urban population now surpassing 50\%, there is a growing focus on the built environment as a determinant of urban health inequality and concomitantly as a setting for public health intervention. The WHO Commission on the Social Determinants of Health (2008) has recently cast light on this problem, pointing out that $32 \%$ of the world's population $(6 \%$ in developed countries) now dwell in what the UN-HABITAT defines as "slums" ${ }^{1}$ as evidence of the severe polarizing consequences of the urbanizing world. Canadian cities are not exempt from calls for a higher level of scrutiny toward glaring disparities in urban environmental quality (UNFPA, 2007). For example, the neighbourhood known as the Downtown Eastside (DTES) in Vancouver, Canada has since the mid- $20^{\text {th }}$ century been nearly universally maligned as an appalling social and aesthetic blight on an otherwise much-envied global metropolis, a glaring discrepancy in a city that is consistently rated as one of the most livable in the world (Economist Intelligence Unit, 2009).

Resolving the stubborn growth of health disparities in Canadian cities continues to evade urban planners and public health practitioners as air pollution (Buzzelli and Jerrett, 2004), toxic hotspots (Lambert et al, 2006), food deserts (Larsen and Gilliland, 2008), traffic hazards (Schuurman et al, 2009), low-income housing conditions (Chaudhuri, 1998) and myriad other environmental conditions continue to worsen over time, even when the overall trend is toward improved quality of life for better-off urban dwellers. Some commentators have suggested that such problems are no longer simply a result of misinformed urban planning and environmental management policies, but have become symptomatic of an impending social breakdown exacerbated by a systemic loss of faith in our governing institutions (Wacquant, 2008; Bourdieu, 2003). In Vancouver, a long tradition of civic unrest aimed at various state and private sector interest groups ranging from real estate developers, police, 2010 Winter Olympics organizers, and other authorities - often taking place on the streets of the inner city - provide abundant evidence of the widening gulf that exists between mainstream political priorities and the concerns of the DTES community and its sympathizers.

At the same time, environmental justice proponents have increasingly targeted those social and institutional forces that have been found to discriminate against inner city populations, as this literature has evolved toward more systemic analysis and action against the structural determinants of inequity as opposed to a mere distributional conflict (Geronimus, 2000; Pellow, 2000; Lake, 1996). Yet while several geographers have contributed to the advancement of environmental justice theory more broadly (Cutter, 1995; Pulido, 1996), to-date, this literature has remained at the periphery of the evolving sub-discipline of health geography. The few

\footnotetext{
${ }^{1}$ Defined as “' a wide range of low-income settlements and/or poor human living conditions.' These areas generally share four characteristics: buildings of poor quality; overcrowding (in, for instance, the number of persons per room); inadequate provision of infrastructure and services; and relatively low price. In many, there is a fifth characteristic - insecurity - because of some aspects of illegality (especially for squatters) or no legal protection for the inhabitants (those who rent)." (cited in WHO Commission, 2008).
} 
environmental justice contributions from geography thus far have focused predominantly on medicalized/epidemiologic approaches that align more closely to a more positivist epistemology (e.g. GIS mapping and modeling of airborne contaminants and concomitant univariate disease patterns), thereby upholding a perspective of environmental injustice based largely on the distribution of environmental hazards (Maantay, 2005; Jerrett et al, 2001). More critical and culturally contextualized interrogations of the complex dynamics between place and the social determinants of health that is characteristic of the "post-medical geography of health" (Kearns, 1993) have been less considered. This gap is particularly curious given the complementary aims of environmental justice and the new public health in achieving health equity for vulnerable populations (Masuda et al, In Press).

In this paper, we address this gap by exploring the utility of a core health geographic concept, the therapeutic landscape, in informing environmental justice theory in the context of a Canadian inner city. Therapeutic landscapes are defined as those settings where the "physical and built environments, social conditions, and human perceptions combine to produce an atmosphere which is conducive to healing" (Gesler, 1996). The concept has figured centrally in the new health geography, especially in its articulation of a more spatially-nuanced, socio-ecological model of health and health inequality (Wilton and DeVerteuil, 2006; Kearns and Moon, 2002). In particular, we draw on empirical evidence from a community-based participatory research partnership in Vancouver's DTES to demonstrate the utility of the therapeutic landscape as the basis for a counter hegemonic approach to knowledge production about the inner city in support of that community's pursuit of justice. In the following sections, we review the environmental justice and therapeutic landscape literatures, particularly as they bear on a more critical understanding of how environmental inequality and health disparity manifest in the inner city. We then look more closely at the DTES as a neighbourhood, providing a brief historical account of how it has come to be widely represented in public discourse as a blighted territory, a way of knowing that has given rise to deficit-oriented planning and disease-focused public health ethics, with resulting impacts on community integrity and health. We then present results from our case study that utilized a photography-mediated technique for local knowledge production. The combination of photography and dialogue in this method allowed us to generate alternative ways of knowing about the health of the neighbourhood, ways that challenge conventional representations of the DTES. Finally, we conclude with some thoughts about how the problembased approach to the DTES as perpetuated by externally imposed interventions may be obscuring and possibly undermining many of the most therapeutic features of the neighbourhood and inhibiting efforts to build a healthier and just community.

\section{Environmental justice and the therapeutic landscape}

\section{Environmental justice in the inner city}

In recent years, environmental justice has become both an increasingly prominent social movement as well as a theoretical lens for interrogating the widening social, environmental and political fissures of what Loic Wacquant (2008) has famously dubbed the "dualizing metropolis" (Teelucksingh, 2002; Howze et al, 2004). As a movement, environmental justice has become a new "master frame" (Taylor, 2000) that has forced a reconsideration of the exclusionary practices of mainstream environmental governance that, under the guise of a management philosophy of regulation, protection, and conservation, have subjugated people and displaced 
them from their homes, whether they be located in city neighbourhoods or traditional territories. At the same time, inattention to the limitations inherent in these policies results in more environmental risks being placed in the midst of low-income, Aboriginal, and ethnoracial minority communities while they are excluded from more affluent and often "white" communities. In exposing these discriminatory practices, environmental justice has brought environmental concerns of the people much closer to real places where people live, work, and play - in essence, by discursively and sometimes literally repopulating indigenous lands, industrialized brownfields, and deteriorating inner city neighbourhoods with the in situ communities that occupy these places, and demanding redress and change (see Haluza-Delay, 2009).

As a theory, environmental justice has become more than just an accounting of the uneven distribution of environmental harms and benefits; it is now widely understood to be a critical and systemic response to social and political structures and processes that have treated vulnerable populations unfairly or that have resulted in their underrepresentation in various approaches to environmental governance (Pellow, 2000; Pulido, 1996). Moreover, recent Foucauldian-inspired scholarship on the environment has articulated a discursive approach to understanding how injustice unfolds in the production and perpetuation of environmental knowledge. These works have located environmental injustice at the intersection between power and those expertmediated environmental institutions that have consistently marginalized Indigenous and grassroots voices since the emergence of the contemporary ecological sciences in the $19^{\text {th }}$ century (Darier, 1999). Key to the notion of justice in the modern era is the recognition that the silencing of these voices has been a result of the downward dissemination of environmental regulation and management through technologies of active citizenship, which have arguably been designed more to reign in dissent than to provide a democratic platform for equal environmental rights (Agrawal, 2005; Masuda et al, 2009; Darier, 1999).

In the inner city, environmental justice has provided an entry point for urban researchers to partner in solidarity with socioeconomically marginalized and racialized populations in efforts to mobilize against those forces that have historically relegated them to the city's hazardous, neglected, and stigmatized territorial margins (Howze et al, 2004; Minkler et al, 2008). For example, in a study of a neighbourhood-based cumulative exposure assessment piloted by the U.S. Environmental Protection Agency in Greenpoint/Williamsburg, New York, Corburn (2002) demonstrates how a shift from expert-mediated risk assessment to a more nuanced and locally generated observational account of real exposures and experiences can lead to a more robust characterization of the risks faced by the community. Similarly, Minkler et al (2008) provide evidence from research-community partnerships in places like Harlem and Southeastern Los Angeles to show how local knowledge can be generated to resolve long-standing environmental injustices. Taken together, studies like these provide support for a research-supported environmental justice activism that confronts conventional techno-scientific deliberative approaches to environmental decision-making that are accused of co-opting the voice of the community and providing legitimacy to the inequitable development of the city. It is within these alternative, often repressed, experiences in the evolving inner city that we suggest the therapeutic landscape concept can be theoretically instructive for a more robust and activist view of environmental justice for the inner city. 
The therapeutic landscape as counter-hegemonic environmental knowledge

With the cultural turn in health geography nearly two decades ago, the concept of the therapeutic landscape has ascended to the sub-discipline's theoretical forefront as an analytic lens for making sense of the complex interrelationship between the places of human experience and health (Gesler, 1992; Williams, 1999). While initially focused on places that have developed a reputation for physical or spiritual healing such as pilgrimage sites and spas (Gesler, 1996, 1993), the literature has steadily expanded to include studies of places that have been subjected to planned clinical, psychosocial, and even embodied interventions, including hospitals (Andrews, 2004), youth camps (Dunkley, 2009), zoos (Hallman, 2007), and yoga studios (Lea, 2008). Additionally, earlier attempts to characterize the intrinsic features of certain places have given way to an understanding of qualities about place - access to nature, opportunities for quiet and solitude, and so on - that are commonly seen as conducive to healthful experiences (Conradson, 2005). Importantly, such qualities are often contested and perceived differently according to social position (Dyck and Dossa, 2007), lifestage (Milligan and Bingley, 2007), or ethnicity (Wilson, 2003).

In recent years, many scholars have extended the prevailing focus on "exceptional" places by examining the therapeutic dimensions of everyday life, including the cities, neighbourhoods, and homes where people live, work, and play (Gesler, 2005). Importantly, much of this work has taken a specific focus on local experiences of health inequality, applying the concept to more stigmatized and marginalized places such as post-industrial cities (Wakefield and McMullan, 2005), soup lines (Johnsen et al, 2005), and the homes of socially marginalized immigrant women (Dyck and Dossa, 2007). A key idea that has emerged from these studies is pointed out by Gesler (2005), that “...some landscapes may be unhealthy and unsavoury, at least to some, but in these 'unsalubrious' settings the redeeming features of a place may be emphasized by local residents" (p. 296). In other words, the therapeutic potential of place is neither universal nor fixed, but is a relational construct, a negotiation where people must find ways to reconcile their perceptions of health with their experiences of their local environments and circumstances, even under conditions of relative depravity (Conradson, 2005; Gesler, 2003). What remains to be seen, however, is whether these redeeming features are merely psychosocial coping responses or can be used as the basis for resistance against those forces responsible for creating and sustaining such unhealthy and unsavoury conditions.

To uncover the latter possibility, several studies have applied psychoanalytic and poststructural ideas about identity, discourse, and power to deepen the theoretical analysis of the therapeutic relationship between people and place. These studies have shifted the emphasis from the intrinsic or perceived healing or health promoting qualities of specific places toward a more discursive analysis of how therapeutic landscapes are constructed, and by whom, amidst the social, political, economic, and cultural forces that together constitute place, whether that be at the scale of the home, the neighbourhood, or city (Massey, 1994). For Dyck and Dossa (2007) the therapeutic landscape of the home as constructed by immigrant women caregivers living in Vancouver, Canada is contingent on their own transnational identity with their relative positioning in Canadian society as the marginalized "other." Their findings reveal that the conditions under which women struggle to make "healthy spaces" for their families are constrained by dominant narratives of Canadian identity that require an ability to participate in Canadian society as an "appropriate" cultural body. 
At the neighbourhood level, Wilton and Deverteuil (2006) apply a Foucauldian analysis of residential alcohol recovery programs in California through which they see therapeutic landscapes as sites of governmentality. Here, therapeutic spaces constructed under the auspices of support and recovery are simultaneously employed as techniques to enable control over both individual behaviour and to facilitate neighbourhood spatial surveillance. Their analysis is particularly instructive in revealing the power of place-making agendas in conveying moral judgements about the people who occupy those places (in this case, associating low-income neighbourhoods with alcoholic residents). Critically, failure to abide by the rules of such therapeutic spaces (i.e. resistance) are seen as grounds for expulsion from these programs, and by extension, the surrounding community, thus revealing the politicized nature of therapeutic landscapes, which is relevant to our own questions of justice and equity.

Finally, at the level of the city, Wakefield and McMullan (2005) have traced how individuals living in the industrial city of Hamilton cope with living in a place reputed for its negative influences on health by disassociating their own experiences of place from dominant representations of the city. Their research suggests a role for community-based narratives as discursive resistances against the stigmatizing discourses of outsiders, even if not necessarily accompanied by overt action. In other words, therapeutic narratives can provide a basis for people to assert their own sense of control over health and place, even in cases where deleterious environmental conditions are evident.

In sum, we find from the literature that therapeutic landscapes are discursively constructed and imbued with power at scales from the home to the city, and beyond (MacKian, 2008). Narratives about the therapeutic benefits of place may be highly politicized and contested as different groups propose competing views about what features make a place more or less "therapeutic". In the rest of this paper, we provide empirical evidence from a case study of the DTES neighbourhood in Vancouver, Canada, to demonstrate how different therapeutic perspectives and interventions are rooted in discourses about the inner city and have come into conflict as "outsider" views have helped to legitimate urban planning and public health agendas of redevelopment and rehabilitation that, in so doing, have undermined local perspectives about the qualities of the neighbourhood and threatened the very existence of the community.

\section{Vancouver's Downtown Eastside as contested space}

\section{Colonization}

In describing the history of contested space in Vancouver's DTES we first acknowledge its dispossession from the indigenous Coast Salish peoples of the Skwwwú7mesh (Squamish), Tsliel-waututh (Burrard) and Xwméthkwyiem (Musqueam) Nations. These original inhabitants of present day Vancouver never ceded their traditional territories to the government, nor their rights as sovereign First Nations, despite centuries of colonial oppression that have rippled through the fabric of Canada's First Nations through exploitive international economic relationships, local experiences of territorial dispossession, and individual suffering from disease, addiction, and social marginalization. The European occupation of Vancouver is important to understanding the more recent evolution of the DTES from a frontier mill town in the late $19^{\text {th }}$ century to the inner city neighbourhood that exists today, particularly as it relates to 
experiences of the $9 \%$ of its current residents who are registered as Status Indians under the federal government Indian Act (versus 1\% for the City of Vancouver; Statistics Canada, 2006). Even in its earliest incarnation, the DTES had acquired features that are familiar even over a century later: the logging industry and port attracted a transient population of workers to social outlets such as brothels and drinking establishments which were accompanied by growing perceptions of criminality and stigmatization by outside observers from the more affluent classes (McDonald, 1996).

\section{The Japanese-Canadian Internment}

Prior to World War II, the rapid growth of Vancouver and eventual westward relocation of its downtown core away from the mills operating on the Burrard Inlet led the DTES to become an affordable, if polluted, neighbourhood for working class families and new immigrants, including Canada's first Japanese-Canadian population who provided a workforce for the mills. With the increasing ethnoracial heterogeneity in the Asian districts of Chinatown and Japantown (both precursors to the modern day DTES) came a steady rise in racial anxiety in the city, first manifesting in the anti-Asian riots of 1907, and later stoked to new proportions by military events taking place across the Pacific. The arrival of World War II provided a convenient rationale for the implementation of racially motivated policies that resulted in the forfeiture of Japanese Canadian property and assets in the DTES, the displacement of families to internment camps, and the occupation of their community by the Armed Forces. After wars-end these properties were not returned to their rightful owners, but were sold off to unscrupulous land speculators who would exploit the social and economic vulnerabilities of successive waves of migrant workers, immigrants, and low-income people, thus steadily transforming the neighbourhood into a profit-making skid row of cheap, deteriorating hotels and rooming houses (Adachi, 1991).

\section{The Moral Configuration of the Contemporary "Inner City": Media, Research, and Community} In the geographically constrained lower mainland of $\mathrm{BC}$, real estate is at a premium as property values have skyrocketed in recent years. The early $20^{\text {th }}$ century architectural heritage of the inner city (see Figure 1) has made the areas surrounding the DTES particularly vulnerable to revitalization schemes that would justify the eastward re-colonization of the affluent classes into Gastown in the 1980s, Yaletown in the 1990s, and Railtown and Chinatown in the $21^{\text {st }}$ century. Yet, possibly in close relation to these patterns of encroachment, there has been an ongoing label attached to the DTES as "Canada's poorest postal code." This phrase exemplifies descriptions of the neighbourhood promulgated mainly by the mainstream media and repeated widely in circles ranging across political campaigns, police strategic plans, health policies, research reports, and the everyday casual conversations of Vancouverites. For example, recent attention given to the neighbourhood in the lead up to the 2010 Winter Olympic Games in Vancouver/Whistler have named the DTES as "our nation's slum" (Figure 2). Similarly, Woolford (2001) has characterized hundreds of negative descriptors in newspaper accounts of the HIV/AIDS epidemic that are used to construct a negative moral configuration of the neighbourhood. In such a configuration, the DTES represents a tainted space defined only by the depravity of its residents and their threat (as disease vectors) to the health of the remainder of the city. With heightened media coverage surrounding the 2010 Olympic Games, political anxiety about the DTES has reached new levels of intensity. A resulting slough of neighbourhood renewal imperatives are now in full swing as city planners, police, and public health officials react to 
political pressure to do something about the highly visible depravity that is witnessed by passersby on the streets of the DTES (City of Vancouver, 2009).

In public health research, descriptions of the DTES may differ from the mainstream media in projecting an aura of detachment, but most often also lead to the conclusion that rational and professional intervention is necessary to improve the wellbeing of the neighbourhood's residents. The biomedical literature has been particularly problematic in its emphasis on the neighbourhood's role as a site of disease, a problem which researchers suggest not only impacts DTES community members, but threatens to spread and affect distant neighbourhoods and cities (Wood et al., 2000; Rachlis et al., 2008). For example, researchers conducting quantitative analyses frequently cite residence in the DTES as a potential risk factor for hepatitis C, overdose, and other negative outcomes (Table 1). There is limited plausibility to the notion that the neighbourhood itself influences such outcomes; rather DTES residence is used as a place-based proxy variable for less tangible factors such as the influence of the gang-controlled drug market, inadequate housing, or poverty. As such, presenting neighbourhood of residence as a predictor of these outcomes without discussion of its proxy status problematizes the neighbourhood and its residents. In sum, these and other descriptions portray, and thus help perpetuate, a neighbourhood defined by the poverty and ill health of its residents and the illegal activities on its streets. With the problems thus named and the readership incited, it is only logical that urban planners and health practitioners aim to "dilute" poverty and disease through dispersal of existing residents and gentrifying the neighbourhood to attract new ones, and to reduce unsanctioned activities through intensified police scrutiny.

Community-embedded social service agencies and charities, too, have often characterized the DTES as an interventional space, even as their staffs are motivated in most cases by a sincere desire to help ${ }^{2}$. Through selected programs, particularly those of community health and food provision agencies, DTES residents are often communicated as mere numbers as efforts are made to exert a positive control of their lives (Allen, 1993, VANDU Women Care Team, 2009). The quantitative results of these programs are then communicated in public relations, grant applications, and reports so as to bolster efforts to secure additional funding in order to maintain services argued to be essential. Ultimately, the discourses of reporting and fundraising, while serving as essential stopgap measures for the community in the face of governmental abrogation from its obligations to the poor, the mentally ill, Aboriginal people, victims of sexual and family violence, and vulnerable youth, also serve to extend and expand the reach of the welfare mentality at the risk of further stigmatizing DTES residents and reifying the need for yet further intervention. In consequence, such agencies, many of which are rooted within the neighbourhood and whose aims are in solidarity with the community, may be seen as exacerbating some of the very problems they seek to ameliorate. For example, low-income parents who raise children in the DTES in order to take advantage of important nutritional and parental supports of community based organizations can face heightened scrutiny from child welfare authorities (Bennett and Sadrehashemi, 2008).

\footnotetext{
${ }^{2}$ We are loath to cite specific examples as we believe this would risk further fueling the already highly politically charged status of research in the DTES. Examples are easily found merely by typing "DTES" into Internet search engines.
} 
While narratives of media, academic, and social services reporting have dominated representations of the neighbourhood, DTES residents and their allies have not been silent. In the face of continuing stigmatization, community activists have gained a reputation for drawing attention to the external sources of pressures on their neighbourhood and the resilience of its inhabitants created through local mechanisms of mutual support (see Carnegie Community Action Project, 2009). Yet despite local resistance to outside interventions, the general zeitgeist of research and government policies and programs remains void of any therapeutic discourse about the inner city landscape as a potentially healing place. We attempt to add such discourses to the voices of activists and community members by exploring some of the healing features of the neighbourhood and discussing the incompatibility of these features with the externally imposed and largely middle class visions of politicians, urban planners, and real estate developers.

\section{The Downtown Eastside as a Therapeutic Landscape}

To challenge the dominance of media, research, and welfare narratives, we have developed a community-based participatory research partnership aimed at articulating suppressed therapeutic discourses of neighbourhood inhabitants as a strategy to pursue inner city environmental justice. As academic and community-based learners within Partnering in Community Health Research, a CBPR training program based at the University of British Columbia, we obtained seed funding in $2007^{3}$ to undertake a pilot project designed to assess the capacity of community-based organizations to undertake environmental justice activities in Vancouver's inner city. Through a series of key stakeholder interviews, partnerships began to emerge whose representatives agreed to participate in further investigation of residents' perspectives of environmental health in the DTES. Using an adaptation of Photovoice, a qualitative photographic research method that combines participant photography and dialogue with a specific focus on social action (Wang, 1997; Wang et al., 1998), we documented experiences of healthy and unhealthy aspects of the neighbourhood as identified by volunteer community-based photographers. Participants were recruited through our partners, and over the course of several months, explored ways to connect their everyday experiences of life in the neighbourhood to systemic inequities rooted in institutional inner city discourses. The overarching aim of the research partnership, which is ongoing at the time of writing this article in 2009, is to develop counter-hegemonic knowledge that is located in and controlled by the community and is used to assert community claims in urban planning and policy development that have traditionally subordinated their perspectives to expert opinions and practices.

In this section, we present the images and words of a pilot project involving community participants ( $\mathrm{N}=9$ ) who, between January and June of 2009, undertook a process that involved (1) a group training and discussion session (3 hours), a two-week photography activity during which participants photographed one roll of film and entered information about their photos into personal logs, (3) an individual interview to discuss their photographs (1 hour), and (4) a final group conversation to synthesize knowledge and develop a community poster for the dissemination of results ( 2 hours). The results of the Photovoice process yielded six overarching themes through which participants articulated their experiences of life in the DTES (see Table 2). As a whole, these six themes provided compelling and detailed accounts of both positive and

\footnotetext{
${ }^{3}$ See acknowledgements
} 
negative dimensions of places in people's lives, including how they came to exist, as well as their encounters with the institutions that govern the spaces of the DTES (HICE, 2009). For the purposes of this paper, we draw out several cross-cutting threads from these themes in order to produce four overarching narratives that refer to key places and place-based practices in the DTES. In weaving these threads together we discovered, and participants confirmed, a paradoxical relationship that DTES residents have between the important places in their lives and the deplorable conditions in their city that have been created by years of economic deprivation and social marginalization. Together, the following four cross-cutting narratives ${ }^{4}$ convey an overarching idea that emerged from the Photovoice process: that despite the neighbourhood's reputation which rests mainly on its many unhealthy elements, the DTES is a place that encourages healing through acceptance, solidarity, and community, even as such places are threatened by urban policies that continue to encourage surveillance, behavioural control, displacement, and eventually gentrification and the re-colonization of the neighbourhood by the middle class. Where appropriate, we also provide supporting background information taken from community reports and interviews with community key stakeholders to add context to participants' views.

\section{Neighbourhood Spaces: The Streets Are Our Living Room}

The first cross-cutting narrative among Community Photographers was the importance of the DTES as a public social space. For example, a photograph of youth-occupied improvised tents on the street taken by Jim (Figure 3), evoked from him a perspective on the meaning of sidewalks in the neighbourhood:

These are young people... just on their own they are kind of huddling...people are humans, and the fact that they are bonding together for company, for protection, so they're not alone... And you see that spontaneously, it's in us, people at their very bottom standing in line-ups for food and the street markets, sidewalks full, make endeavors to give things to each other.

In stark contrast to the sense of belonging on the sidewalks of the DTES, Louise describes an incident in another neighbourhood:

I went up to Kitsilano [a wealthier Vancouver neighbourhood] and there was a festival on the weekend and there was a man picking empties out of the garbage can and this big loud somewhat overweight real-estate agent was standing with his friends and started mocking this man and making fun of him and making jokes and they were all laughing, and I just thought that would not happen in the Downtown Eastside.

Taken together, these photos inspired participants to reveal a paradoxical combination of push and pull forces that are involved in reproducing this narrative of acceptance and tolerance within the spatially marginalized neighbourhood. On the one hand, Louise suggests that people like her are pushed into the DTES by a perceived sense of trespass when transcending the boundaries of the neighbourhood. On the other hand, people who are rendered vulnerable by broken homes, addictions, or other forms of social and cultural othering (e.g. homeless youth, GLBTQ, and aboriginal communities) are pulled into the neighbourhood because of a perceived tolerance of poverty and acceptance of differing norms of behaviour in the inner city that permit "street families" to live in a way that supports their members. However, such acceptance is not without its own ambiguities and contradictions as the accepting nature of the community can also be

\footnotetext{
${ }^{4}$ In-depth methodological details are available upon request to the corresponding author.
} 
accompanied by exclusionary and possibly exploitive circumstances and practices, including problematic social networks of drug users and dealers (themselves externally facilitated by the gangs who control the DTES drug and sex trades) as well as emotionally and physically abusive intimate relationships which may exacerbate negative consequences of street-involved lives (see similar discussion by Wolsch and Rowe, 1993).

Further reinforcing the importance of street spaces, the execrable conditions of single room occupancy hotels (SROs) in the DTES are on the one hand fully consistent with the UNHABITAT definition of "slum" (WHO). Yet ironically, these conditions are also a key contributor to public street life as the intolerably cramped rooms, poor sanitation, surveillance, and restrictions that typify the indoor spaces of SROs help to foster a sense of community in the neighbourhood's outdoors. Being forced to commune on the streets gives rise to a community culture where, as reported in an interview with one key stakeholder, sidewalks are thought of as "the living room of the neighbourhood". Such a street culture, however, directly confronts ongoing police and private security efforts to maintain order and mitigate the perceived criminality of the neighbourhood streets (see also Howard et al, 2002). Two recent examples are particularly instructive. First, periodic police campaigns, most recently reported in 2009, to remove "structures" (defined as a temporary or permanent shelter from the elements) from DTES streets, alleys, and parks has led to the seizure of dozens of individuals' belongings (Eby 2009, personal communication). As a final insult, many of these street residents are periodically given fines for bylaw violations, thus placing them even further under the surveillance of law enforcement as few have any intention or capability of paying such fines. The campaign has not, however, led to improvements in those individuals' living situations as such structures invariably return shortly after each wave of police vigilance passes. Rather, the primary impact has been to shield passers-by from the sight of makeshift encampments, often, and likely not coincidentally, in the lead up to major public events such as the upcoming 2010 Olympics. Similarly, several study participants commented on another assault on street life driven by a similar philosophy in the now-defunct city program called the "Downtown Ambassadors". Under this program, private security guards hired by local business improvement associations were publicly promoted as a way to assist the thousands of tourists who regularly visit the city. But among DTES circles the Ambassadors have been accused of functioning primarily to remove unsightly community members from public and private spaces through unrelenting surveillance, threats, and harassment (Bennett et al, 2008). According to participants, the endpoint of such policies is the human sanitization of public spaces that are aesthetically prepared for future occupation of middle-class residents while being made increasingly inaccessible to those who have found meaningful connections with others on the streets of the DTES, even as they are excluded from the rest of the city.

\section{Home Spaces: Redemption Amidst Squalor}

A second theme also relates to the paradoxical impacts that SRO conditions have on community life in the DTES. Amber is a young woman living with mental illness who has resided in the DTES for many years. She spoke of the DTES as a place where she has found safety and security despite the challenges she has faced from combined experiences of poverty and social isolation that have resulted from her illness. She chose an image of her own apartment (Figure 5) to convey the hidden opportunities she has experienced within SRO life that have helped her to 
redeem herself from a perceived self-blame for her life situation, even amidst the squalor surrounding her:

You can be healthy in these rooms. There's a lot of things that are bad about it. But the reason why everybody stays in these rooms, is because it's theirs. Despite all the craziness and all the unhealthiness, it's mine, and nobody could tell me that I couldn't come home...Despite the black mould and all those other things, most people that have ever faced homelessness have been in a lot more dangerous situations.

Despite Amber's sympathetic evaluation of her home, the ambivalence in her words provide an important cautionary to the temptation to romanticize the poverty of the DTES and to evoke simplistic solutions such as 'cleaning up' the SROs in order to improve health (see also Hoch and Slayton (1989) for an early account of the impacts of such solutions). Amber's reflection on her housing situation shows that, while the neighbourhood has offered her and others an opportunity to claim a home for themselves, there is a direct relationship between the affordability of SROs and their hazardous conditions, as rents are generally set in accordance with provincial housing allowances, an amount that provides landlords with little room for upgrades, let alone regular maintenance. As a result of underinvestment and outright failures of public health and housing policies, people are routinely subjected to environmental (bedbugs, mould), psychosocial (visitor restrictions, abuse from landlords), and criminal (sexual violence, drug trafficking) threats in their housing situations. Among other factors, these dangers have been attributed to the City of Vancouver's lack of enforcement of existing bylaws within the borders of the DTES, under the notion that such enforcement would necessarily drive SRO operators out of business (Pivot Legal Society, 2006). Even the questionable sanctuary of the $\mathrm{SRO}$ is threatened by encroaching gentrification, as the number of these low-cost units is declining as a result of new condominiums and conversions of existing housing stock to other higher-priced market housing units intended for middle class gentrifiers (e.g. students, artists) (CCAP, 2008; Eby and Misura, 2006). These new units certainly mitigate the negative appearance of the existing housing stock, but at the price of excluding community members in financially vulnerable positions, many of whom end up on the streets or are displaced from the neighbourhood with its associated social supports and services.

\section{Public Parks: Green Vs. Gathering Places}

Much of the urban environmental justice literature emphasizes the importance of a positive green aesthetic in creating healthy communities (for example, Ferris et al., 2001; Agyeman, 2002). In an interesting contrast, participants spoke little about greenery and more about the importance of parks as gathering places, even though the condition of these parks are little more than empty fields and street corners. For example, Figure 4 depicts Oppenheimer Park, a one-block area in the DTES that has a playground, baseball diamond, meeting spaces, and a city-run arts facility. It is also a place that is imbued with a long and highly politicized history as the locus of the 1907 anti-Asian riots (Adachi, 1991), the site of labour rallies during the 1930s (Ellison, 2007), and the field for the highly reputed Asahi Japanese-Canadian baseball team prior to WWII. Despite the long historical importance of Oppenheimer Park, it is widely regarded today among Vancouverites as a haven for the homeless and addicts to participate in unsightly or unruly behaviours. 
Janie, a longtime user of the park, suggested that the Oppenheimer has a profoundly different meaning to local inhabitants. Janie is a transgendered HIV+ woman with a strong commitment to social activism which stems from her experiences of past drug addiction and housing instability. She described how at Oppenheimer Park one can:

...Meet people at the benches and watch whatever is happening... It's just a place that you can go and you're sure you're going to run into somebody, and you can sit down and have a discussion with them, and there are so many people that talk about this community.

Yet the very function of the park as a neighbourhood meeting place makes it vulnerable to the impositions of planners driven by a desire to improve its aesthetic appearance (by removing its unaesthetic elements and inhabitants) in preparation for the 2010 Winter Olympics. In 2009, a well-funded civic upgrade to the park has rendered it closed to the public for landscaping purposes. A nearby street corner popularly known as "Pigeon Park" has currently been subjected to a similar enclosure. In many participants' eyes, embedded into the redesign of these parks are policies that are meant to regain city control over park activities. For example, there have been repeated police eviction of people camping in Oppenheimer Park over the years, and many historical features of the Park such as the underused Asahi baseball diamond and aging Cherry trees commemorating the Japanese Canadian Internment have been removed or replaced. According to participants, these measures represent a wrongheaded attempt by civic authorities to erase the park's history to remake the neighbourhood as a more presentable and publicly consumable space. While serving the purpose of preparing the city for the Olympics, they have undermined, possibly irreversibly, one of the key therapeutic elements of the neighbourhood: that is, its status as a communal gathering space that is welcoming to marginalized people in a way most other public spaces in the city are not.

\section{Making Places of Solidarity}

A final key therapeutic element of the DTES landscape identified by participants focuses on the collective sense of place-making that directly confronts the oppression imposed on them by outsiders. Participants identified numerous place-making activities that provided a means assert local control over community life, often by rehabilitating formerly unused or dangerous spaces in order to make them healthy again. Throughout the DTES, there are innumerable instances of street art, guerilla gardens, and informal meeting places that testify to local initiatives undertaken by residents who wish to project their own sense of community onto key places that have been abandoned by others. These internally driven celebratory projects provide a way for individuals to take back the community and establish meaningful and sustainable relationships and social networks. Figure 6 is a photo of a mural on the side of one such place, the Downtown Eastside Neighbourhood House, that was painted by Louise and many other community members in 2008. Louise spoke about the mobilizing effect that making place had on her and others:

It's starting with the Neighbourhood House, it's starting with the artwork on the wall - there was about 200 different people that came and did a little bit of this, a little bit of that. That was exciting for me to see and I felt good about it... because a lot of times we are divided, in this neighbourhood, and that's a problem. Once we are divided, the higher up people, they keep us down that way. But if we are strong and united, then we are strong and they can't divide us anymore.

For Louise, the mural and the Neighbourhood House itself are indicative of the political potential for the idea of making therapeutic landscapes as mobilizing tools for community building in 
places of depravity and oppression, a previously unexplored area in the literature surrounding this concept. Here, a sense of solidarity among community members can be fostered by their connection to specific places in the neighbourhood and used to shape a positive community vision driven solely by and for the residents of the DTES - in this case, catalyzed by a grassroots organization that is committed to providing a safe and welcoming place for residents to share their stories and their lives. Importantly, it is not the mural itself that contributes to the health of Louise' neighbourhood; rather, it is the place-making process by which it was created that was seen to be therapeutic. The key point that emerges is that the community members of the DTES possess their own expertise on what constitutes a healing place in their neighbourhood and do not depend on those interventions designed by outsiders.

\section{Conclusions}

Using a community-based participatory research approach, we have developed a novel method for assessing local experiences of health and place in one Canadian inner city in order to promote a more meaningful conceptualization of environmental justice. A complete accounting of environmental justice in the city must go beyond the measurement of the possible contamination associated with what people breathe, drink, and eat. Addressing injustice in the city requires insight and intervention across the full range of health determinants, from basic individual needs (clean water, food, shelter) to the actualization of vibrant, supportive, and inclusive communities. At the heart of such an agenda are the voices of residents who, in the face of injustice, are fully capable of exerting agency in enabling locally produced knowledges and collective creativity to rebuild and sustain their communities (Cloke et al, 2008). As such, in seeking an expanded role for health geographers in environmental justice, this paper has explored the utility of the therapeutic landscape concept in fostering the assertion of more locally meaningful and counterhegemonic discourses about the inner city as a complex and often health promoting environment, rather than merely as a place of absolute risk and depravity as perceived by outside interveners (Deverteuil et al, 2009; Ekers and Loftus, 2008).

The DTES, as described by urban planners, the media, academia, and even many social service and charitable agencies, is a place where healing occurs only by repudiating the neighbourhood through physical removal of tainted people (by hospitalization, rehabilitation, or incarceration), through psychologically distancing of 'normal' outsiders from the day-to-day life of the neighbourhood (see Cloke et al, 2008), or through dismantling and reconstructing key public spaces in order to ensure they coincide with social and cultural norms preferred by these outsiders. In this way, such discourses may be considered as acts of environmental injustice as they have the effect of simultaneously marginalizing the community within its own space, legitimizing the gentrification of the neighbourhood, failing to acknowledge local identities, experiences, and preferences, and ultimately impeding the realization of the aspirations of the community.

Our results confirm that the DTES neighbourhood is perceived by its inhabitants as a therapeutic landscape in the fullest sense, as participants have reported its importance in realizing their needs for belonging, social interaction, redemption from social marginalization, and solidarity against political oppression. In identifying these narratives, our results challenge many mainstream assumptions about the DTES as a place suited solely for the purposes of public health 
surveillance and police control and in need of revitalization and rehabilitation. Rather, the therapeutic landscape frame helps us to identify ways in which such assumptions may have an undermining effect on those elements of place that are most important to the in situ community that resides there.

Accordingly, we argue that the therapeutic landscape can be immensely helpful for a community-based articulation of environmental justice in the inner city. Our participants have helped us to see how locally identified therapeutic places, while invisible or contradictory to conventional urban revitalization schemes, are key to the integrity and vitality of the community. By helping the community to accumulate knowledge about their neighbourhood as a therapeutic landscape, this approach has the potential to enable the community to re-cast inner city interventions away from externally imposed planning models toward an agenda of neighbourhood autonomy, emancipation, and justice. 


\section{References}

Adachi, K. 1991. The Enemy That Never Was: A History of the Japanese Canadians. Toronto, McClelland and Stewart.

Agrawal, A. 2005. Environmentality: Technologies of Government and the Making of Subjects. London, Duke University Press.

Agyeman, J. 2002. Constructing environmental (in)justice: Transatlantic tales. Environmental Politics, 11, 3, 31-53.

Allen, T. 1993. Someone to talk to: Care and control of the homeless. Masters thesis, Simon Fraser University, Canada.

Andrews, G.J., 2004. (Re)thinking the dynamics between healthcare and place: therapeutic geographies in treatment and care practices. Area 36, 3, 307-318.

Bennett, D., Eby, D., Richardson, J. and Tilley, K. 2008. Security before justice: A study of the impacts of private security on homeless and underhoused Vancouver residents. Vancouver, Pivot Legal Society.

Bennett, D., and Sadrehashemi, L. 2008. Broken promises: Rethinking B.C.'s child welfare system. Vancouver, Pivot Legal Society.

Bourdieu, P. 2003. Firing back: Against the tyranny of the market 2. New York, The New Press.

Buzzelli, M., and Jerrett, M. 2004. Race gradients of ambient air pollution exposure in Hamilton, Canada. Environment \& Planning A, 36, 1855-1876.

Carnegie Community Action Project. 2009. Retrieved August 5, 2009, from http://ccapvancouver.wordpress.com.

CCAP. 2008. Disappearing Homes: The Loss of Affordable Housing in the DTES. Vancouver, CCAP.

Chaudhuri, N. 1998. Child health, poverty and the environment: The Canadian context. Canadian Journal of Public Health 89, S1, S26-S30.

City of Vancouver. 2009. Downtown Eastside Revitalization website. http://vancouver.ca/commsvcs/planning/dtes/.

Cloke, P., May, J., and Johnsen, S. 2008. Performativity and affect in the homeless city. Environment and Planning D: Society and Space, 26, 241-263.

Conradson, D. 2005. Landscape, care and the relational self: Therapeutic encounters in rural England. Health and Place, 11, 337-348.

Corburn, J. 2002. Environmental Justice, Local Knowledge, and Risk: The Discourse of a Community-Based Cumulative Exposure Assessment. Environmental Management, 29, 4, 451-466

Cutter, S.L. (1995). Race, class and environmental justice. Progress in Human Geography 19, 1, 111-122.

Darier, E. Ed. 1999. Discourses of the Environment. Oxford, Blackwell.

Deverteuil, G., May, J., and von Mahs, J. 2009. Complexity not collapse: Recasting the geographies of homelessness in a 'punitive' age. Progress in Human Geography, 33, 3, 646-666.

Dunkley, C.M. 2009. A therapeutic taskscape: Theorizing place-making, discipline and care at a camp for troubled youth. Health and Place 15, 88-96.

Dyck, I., and Dossa, P. 2007. Place, health and home: Gender and migration in the constitution of healthy space. Health and Place, 13, 691-701. 
Eby, D. Executive Director, Pivot Legal Society. Personal Communication.

Eby, D., and Misura, C. 2006. Cracks in the Foundation: Solving the Housing Crisis in Canada's Poorest Neighbourhood. Vancouver, Pivot Legal Society.

Economist Intelligence Unit. (2009). The Economist Intelligence Unit's liveability survey February 2009. Report retrieved 24 July 2009 from http://store.eiu.com/product/464271831.html.

Ekers, M., and Loftus, A. 2008. The power of water: Developing dialogues between Foucault and Gramsci. Environment and Planning D, 26, 698-718.

Ellison, S. 2007. Oppenheimer Park: A study of interconnectivity in the public realm. Masters thesis, Dalhousie University, Canada.

Fairbairn, N., Wood, E., Stoltz, J., Li, K., Montaner, J., Kerr, T. 2008. Crystal methamphetamine use associated with non-fatal overdose among a cohort of injection drug users in Vancouver. Public Health, 122, 70-78.

Ferris, J., Norman, C., and Sempik., J. 2001. People, land, and sustainability: Community Gardens and the social dimension of community development. Social Policy and Administration, 35, 5, 559-568.

Geronimus, A. T. (2000). To mitigate, resist, or undo: addressing structural influences on the health of urban populations. American Journal of Public Health, 90(6), 867-872.

Gesler, W.M. 2005. Therapeutic landscapes: an evolving theme. Health and Place 11, 295-297.

Gesler, W.M., 2003. Healing Places., Lanham, Rowman \& Littlefield.

Gesler,W.M. 1996. Lourdes: healing in a place of pilgrimage. Health and Place 2, 2, 95-105.

Gesler, W., 1993. Therapeutic landscapes: theory and a case study of Epidauros, Greece. Environment and Planning D: Society and Space 11, 171-189.

Gesler, W.M., 1992. Therapeutic landscapes: medical issues in light of the new cultural geography. Social Science and Medicine 34, 735-746.

Globe and Mail. 2009. Our Nation's Slum: Time to Fix It. Cover image for a special series on the Downtown Eastside.

Hallman, B.C. 2007. A 'Family-Friendly' Place: Place identity, leisure and wellbeing - the zoo as therapeutic landscape. Chapter 9 in A. Williams (ed.) Therapeutic Landscapes: Advances and Applications. Aldershot, Ashgate.

Haluza-Delay, R. 2009. Speaking for Ourselves: Environmental Justice in Canada. Vancouver, UBC Press.

HICE (Healthy Inner City Environments). 2009. Health Promoting Inner City Environments: A participatory research approach to reducing environment and health inequities and improving community health in Vancouver. Final Report to the BC Environmental and Occupational Health Research Network. Vancouver, Partnering in Community Health Research.

Hoch, C., and Slayton, R. 1989. New Homeless and Old: Community and the Skid Row Hotel. Philadelphia, Temple University Press.

Howard, T., Jackson, M., Kerr, T., Pacey, K., Richardson, J., Tyndall, M. 2002. To serve and protect: A report on policing in Vancouver's Downtown Eastside. Vancouver, Pivot Legal Society.

Howze, E.H., Baldwin, G.T., and Crozier Kegler, M. 2004. Environmental health promotion: Bridging traditional environmental health and health promotion. Health Education and Behavior 31, 4, 429-440. 
Kearns, R.A. 1993. Place and health: towards a reformed medical geography. The Professional Geographer 46, 67-72.

Kearns, R.A., and Moon, G. 2002. From medical to health geography: novelty, place and theory after a decade of change. Progress in Human Geography 26, 5, 605-625.

Kerr, T., Marsh, D., Li, K., Montaner, J., Wood, E. 2005. Factors associated with methadone maintenance therapy use among a cohort of polysubtance using injection drug users in Vancouver. Drug and Alcohol Dependence, 80, 329-335.

Jerrett, M., Burnett, R.T., Kanaroglou, P., Eyles, J., Finkelstein, N., Giovis, C., and Brook, J.R. 2001. A GIS-environmental justice analysis of particulate air pollution in Hamilton, Canada. Environment and Planning A, 33, 955-973.

Johnsen, S., Cloke, P., and May, J. 2005. Transitory spaces of care: serving homeless people on the street. Health and Place 11, 323-336.

Lake, R.W. 1996. Volunteers, NIMBYs, and environmental justice: Dilemmas of democratic practice. Antipode, 28, 2, 160-174.

Lambert, T.W., Guyn, L., and Lane, S.E. (2006). Development of local knowledge of environmental contamination in Sydney, Nova Scotia: Environmental health practice from an environmental justice perspective. Science of the Total Environment, 368, 471484.

Larsen, K., and Gilliland, J. 2008. Mapping the evolution of 'food deserts' in a Canadian city: Supermarket accessibility in London, Ontario, 1961-2005. International Journal of Health Geographics 7, 16.

Lea, J. 2008. Retreating to nature: Rethinking 'therapeutic landscapes'. Area 40, 1, 90-98.

MacKian, S.C. 2008. What the papers say: Reading therapeutic landscapes of women's health and empowerment in Uganda. Health and Place 14, 106-115.

Maantay, J. 2005. Asthma and air pollution in the Bronx: Methodological and data considerations in using GIS for environmental justice and health research. Health and Place 13, 1, 32-56.

Massey, D. 1994. A global sense of place. In Space, Place and Gender. Minneapolis, University of Minnesota Press.

Masuda, J.R. Forthcoming. "You're loud, you stink, and you're in their face": Governmentality and environmental justice in the city. Under review in the Annals of the Association of American Geographers.

Masuda, J.R., McGee, T.K., and Garvin, T.D. 2008. Power, knowledge, and public engagement: Constructing 'citizenship' in Alberta's Industrial Heartland. Journal of Environmental Policy and Planning 10, 4, 359-380.

Masuda, J.R., Poland, B., and Baxter, J. (In Press). Reaching for environmental health justice through health promotion: A Canadian perspective. International Health Promotion.

McDonald, R.A.J. 1996. Making Vancouver: Class, Status, and Social Boundaries, 1863-1913. Vancouver, UBC Press.

Milligan, C., and Bingley, A. 2007. Restorative places or scary spaces? The impact of woodland on the mental well-being of young adults. Health and Place 13, 799-811.

Minkler, M., Breckwich Vásquez, V., Tajik, M., and Petersen, D. 2008. Promoting environmental justice through community-based participatory research: The role of community and partnership capacity. Health Education and Behavior 35, 1, 119-137. 
Palepu, A., Sun, H., Kuyper, L., Schechter, M.T., O’Shaughnessy, M.V., Anis, A.H. Predictors of early hospital readmission in HIV-infected patients with pneumonia. Journal of General Internal Medicine, 18, 242-247.

Pellow, D.N. 2000. Environmental inequality formation: Toward a theory of environmental injustice. American Behavioral Scientist, 43, 4, 581-601.

Pulido, L. 1996. A critical review of the methodology of environmental racism research. Antipode, 28, 2, 142-159.

Romney, M.G., Gustafson, R. Sandhu, J., Champagne, S., Wong, T., Nematallah, A., Forsting, S., Daly, P. 2008. Clinical Infectious Diseases, 47, 6, 768-774.

Rachlis, B.S., Hogg, R.S., Wood, E., Li, K., Kerr, T., 2008. Factors associated with geographic migration among a cohort of injection drug users. Health \& Place, 14, 536-543.

Schuurman, N., Cinnamon, J., Crooks, V.A., and Hameed, M. 2009. Pedestrian injury and the built environment: An environmental scan of hotspots. BMC Public Health,9,233.

Statistics Canada. 2006. 2006 Census. Government of Canada.

Taylor, D. 2000. The rise of the environmental justice paradigm: Injustice framing and the social construction of environmental discourses. American Behavioral Scientist, 43, 4, 508580.

Teelucksingh, C. 2002. Spatiality and environmental justice in Parkdale Toronto. Ethnologies, 24, 1, 119-141.

UNFPA (United Nations Population Fund). 2007. State of World Population 2007: Unleashing the Potential of Urban Growth. New York, United Nations Population Fund.

VANDU Women Care Team. 2009. "Me, I'm living it": The primary health care experiences of women who use drugs in Vancouver's Downtown Eastside. British Columbia Centre for Women's Health, Vancouver.

Wacquant, L. 2008. Urban Outcasts: A Comparative Sociology of Advanced Marginality. Polity, Massachusetts.

Wakefield, S., and McMullan, C. 2005. Healing in places of decline: (Re)imagining everyday landscapes in Hamilton, Ontario. Health and Place 11, 299-312.

WHO Commission on the Social Determinants of Health. (2008). Final Report of the WHO Commission on the Social Determinants of Health. Geneva, World Health Organization.

Williams, A. (Ed.). 1999. Therapeutic Landscapes: The Dynamic between Wellness and Place. Lanham, University Press of America.

Wilson, K., 2003. Therapeutic landscapes and First Nations peoples: an exploration of culture, health and place. Health and Place 9, 83-93.

Wilton, R., and Deverteuil, G. 2006. Spaces of sobriety/sites of power: Examining social model alcohol recovery programs as therapeutic landscapes. Social Science and Medicine 63, 649-661.

Wang, C. 1997. Photovoice: Concept, methodology, and use for participatory needs assessment. Health Education and Behavior, 24, 3, 369-387.

Wang, C., Yi, W., Tao, Z., and Carovano, K. 1998. Photovoice as a participatory health promotion strategy. Health Promotion International, 13, 75-86.

Wolsch, J.R., and Rowe, S. 1993. On the streets: Mobility paths of the urban homeless. City and Society, 6, 2, 115-140.

Wood, E. Chan, K., Montaner, J.S.G., Schechter, M.T., Tyndall, M., O-Shaughnessy, M.V., Hogg, R.S. 2000. The end of the line: Has rapid transit contributed to the spatial diffusion 
of HIV in one of Canada's largest metropolitan areas? Social Science \& Medicine, 51, 741-748.

Wood, E., Spittal, P., Kerr, T., Small, W., Tyndall, M.W., O’Shaughnessy, M.V. Schechter, M.T. 2003. Requiring help injecting as a risk factor for HIV infection in the Vancouver epidemic. Canadian Journal of Public Health, 94, 5, 355-359.

Wood, E., Kerr, T., Stoltz, J., Qui, Z. Zhang, R., Montaner, J.S.G., Tyndall, M.W. 2005. Prevalence and correlates of hepatitis $\mathrm{C}$ infection among users of North America's first medically supervised safer injection facility. Public Health, 119, 1111-1115.

Woolford, A. 2001. Tainted space: Representations of injection drug-use and HIV/AIDS in Vancouver's Downtown Eastside. BC Studies 129, 27-50.

Table 1. Studies using DTES residence as a predictor of various health outcomes.

\begin{tabular}{|l|l|l|l|}
\hline Author, date & Outcome & $\begin{array}{l}\text { Univariate odds ratio } \\
\text { CI })\end{array}$ & $\begin{array}{l}\text { 95\% } \\
\text { Significant } \\
\text { multivariate } \\
\text { analysis }\end{array}$ \\
\hline Palepu et al., 2003 & $\begin{array}{l}\text { Early hospital readmission for } \\
\text { pneumonia among HIV+ patients }\end{array}$ & Yes \\
\hline Wood et al., 2003 & Self-reported requiring help injecting & $1.1(0.8-1.6)$ & N/A \\
\hline Kerr et al., 2005 & On methadone maintenance therapy & $0.7(0.5-0.9)$ & No \\
\hline Wood et al., 2005 & $\begin{array}{l}\text { Hepatitis C infection among Safer } \\
\text { Injection Facility users }\end{array}$ & $1.57(0.99-2.50)$ & N/A \\
\hline Fairbairn et al., 2008 & Self-reported non-fatal overdose & $1.89(0.96-3.70)$ & No \\
\hline Romney et al., 2008 & $\begin{array}{l}\text { Invasive pneumococcal disease due to } \\
\text { Streptococcus pneumonia serotype 5* }\end{array}$ & $10.25(4.07-25.8)$ & Nocis \\
\hline
\end{tabular}

*"Frequents DTES" rather than "DTES residence" used as risk factor 
Table 2. Emerging and cross-cutting themes emerging from individual and group interviews.

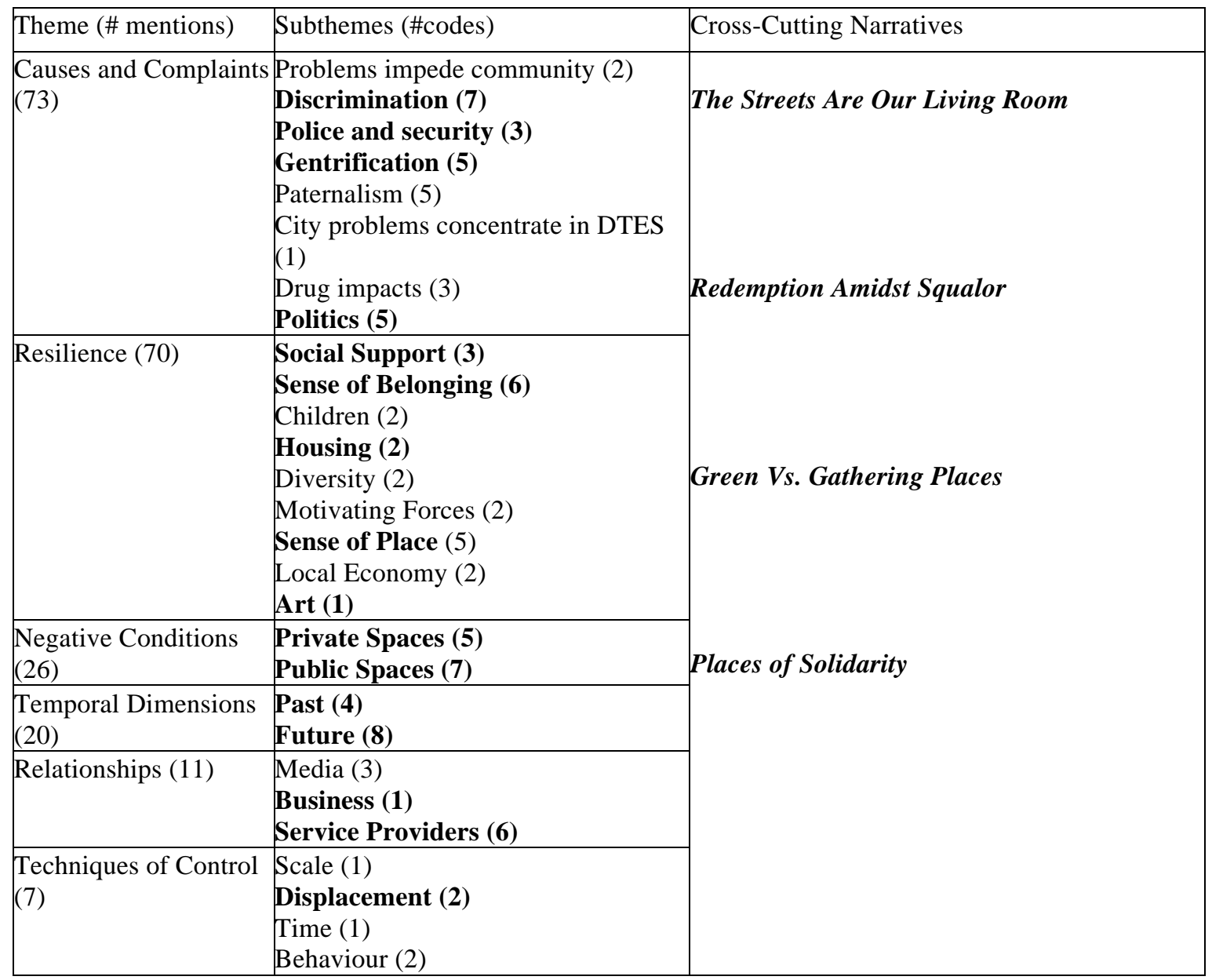

* Subthemes represented in cross-cutting narrative analysis are bolded 


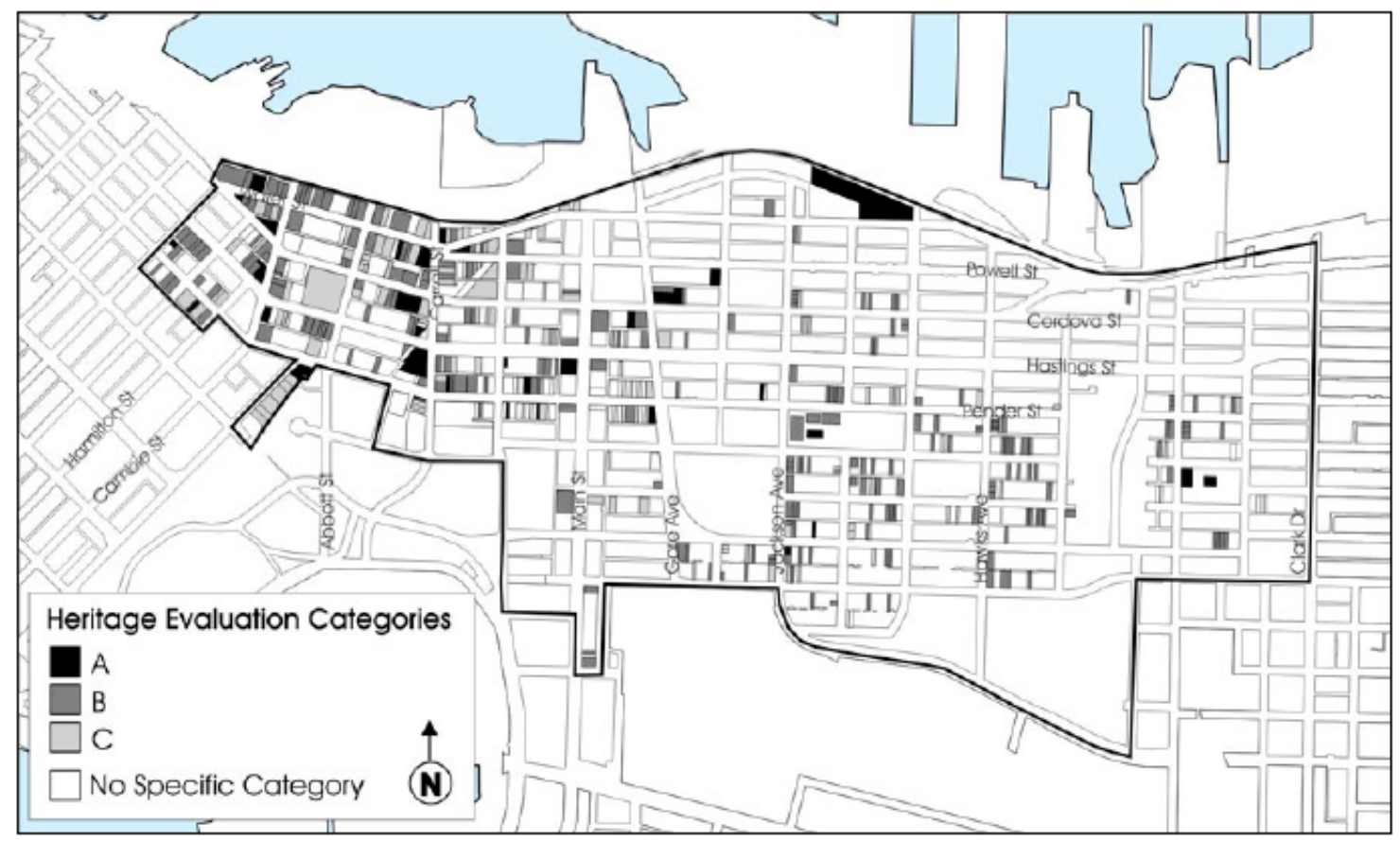

Map of Heritage Buildings in the DTES

Fig. 1. Map of heritage buildings in the DTES. Downtown Eastside Community Monitoring Report (City of Vancouver, 2004). 


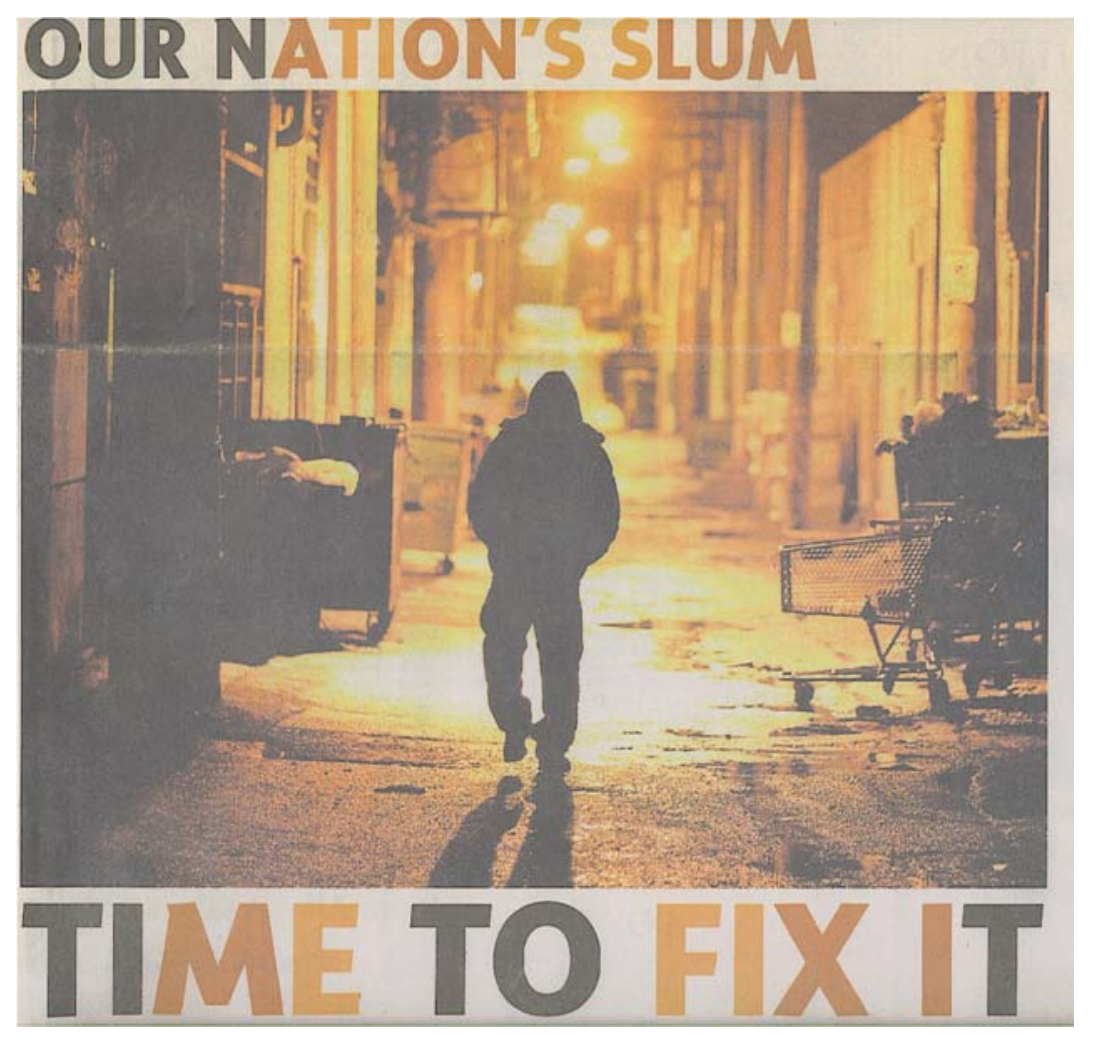

Fig. 2. Front page cover image of a special series on the Downtown Eastside in one of Canada's major national newspapers. (Globe and Mail, 2009). 


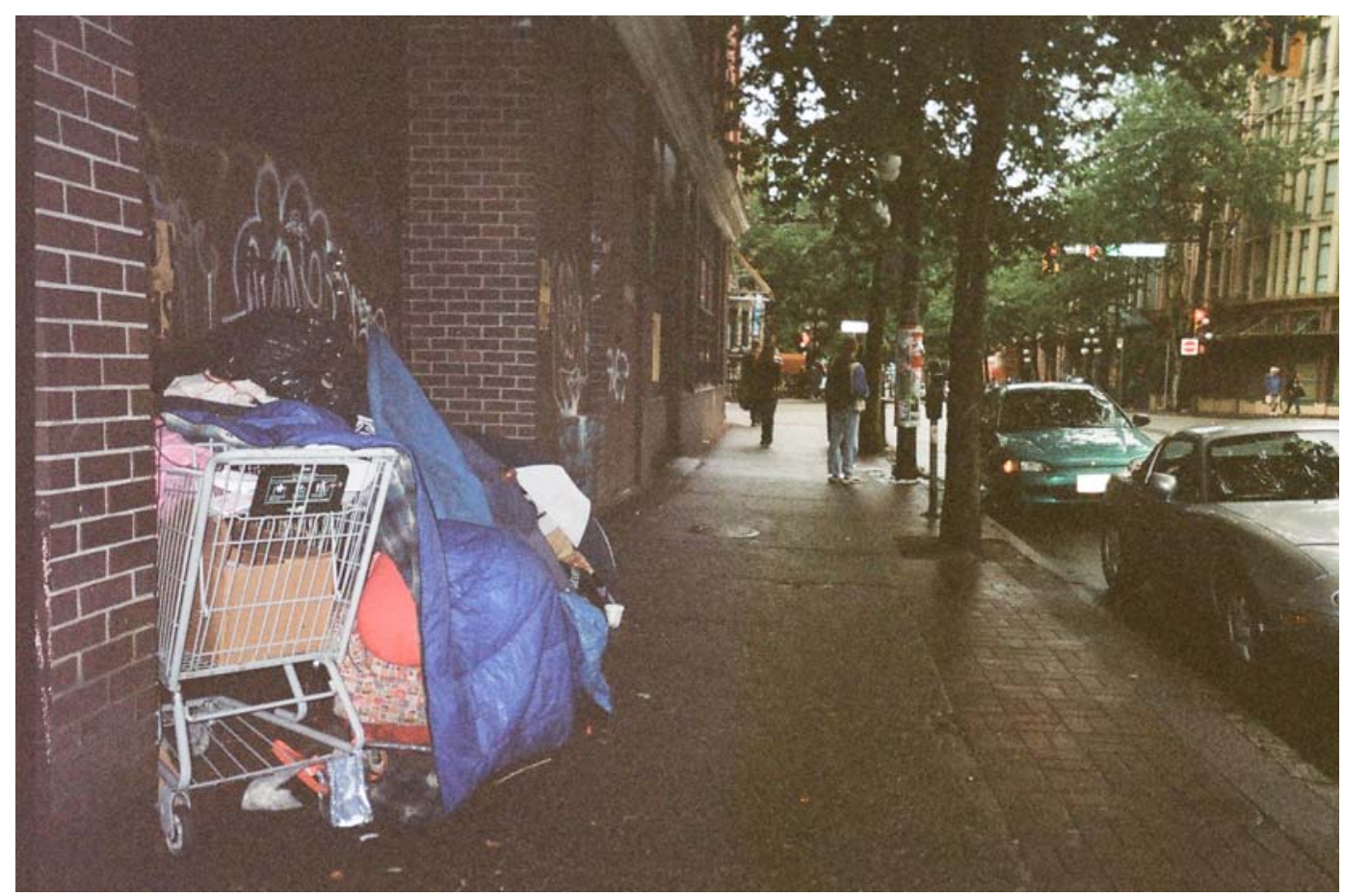

Fig. 3. "Structures" (photo credit: "Jim").

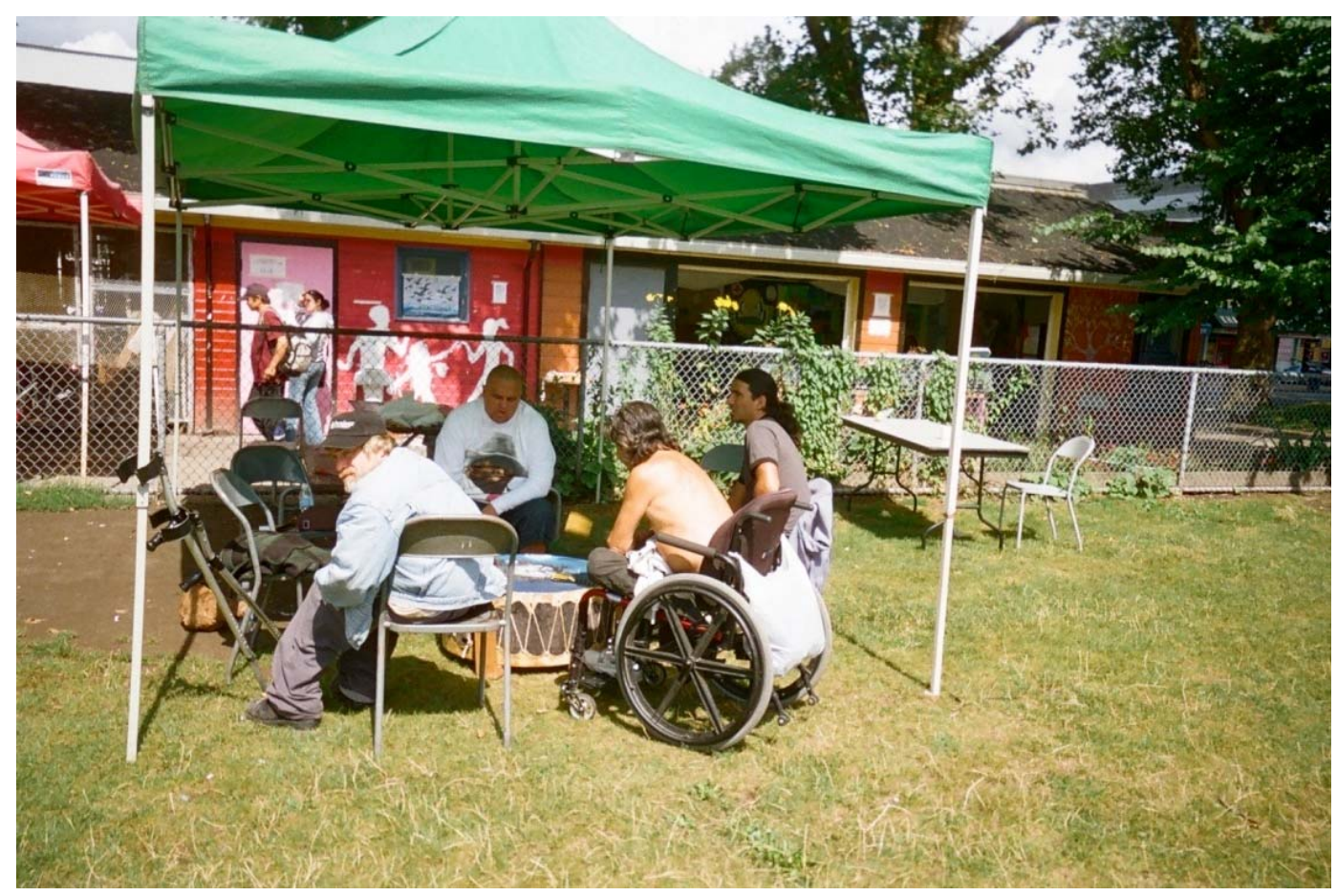

Fig. 4. "Drum Circle" (photo credit: "Leslie") 


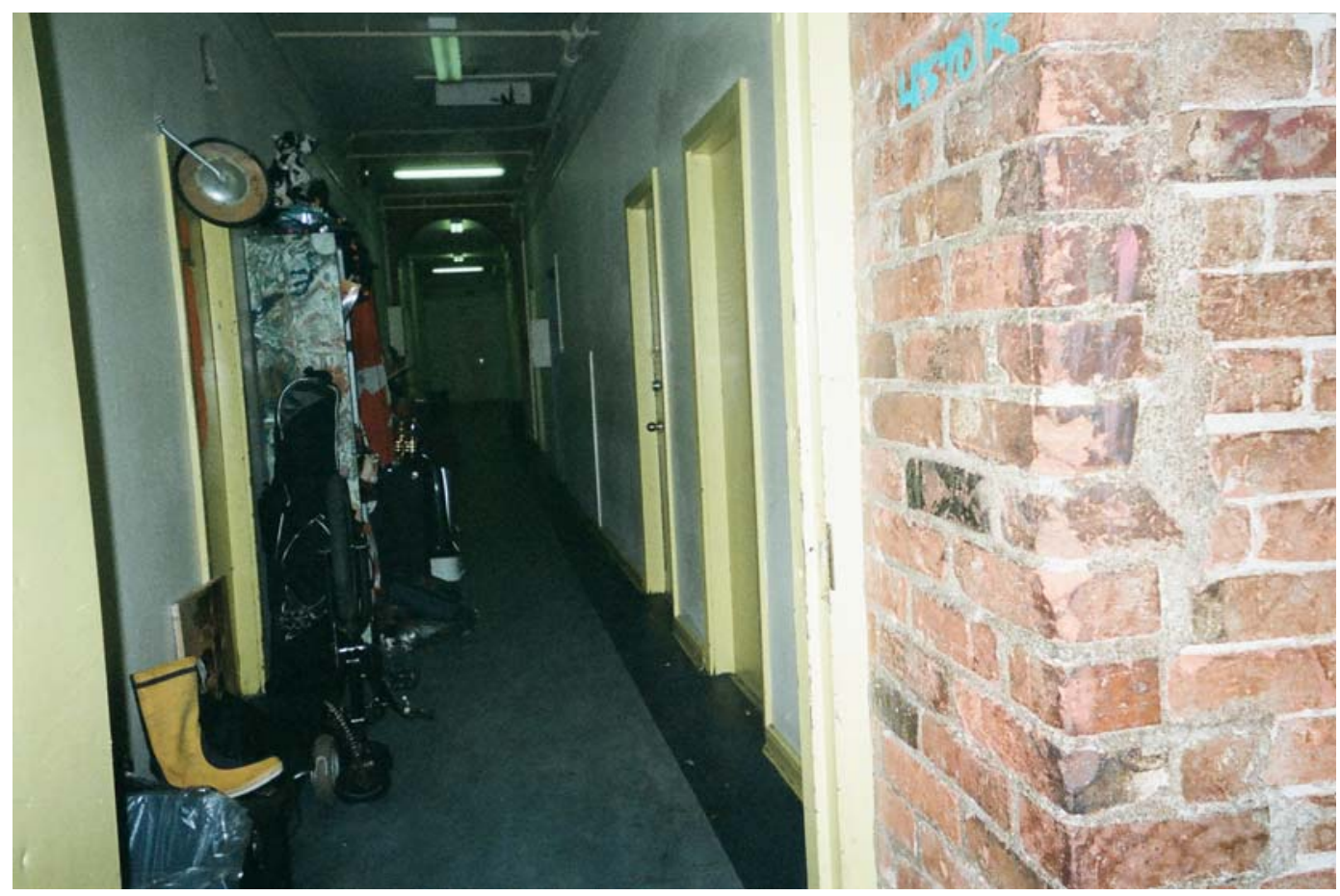

Fig. 5. "SRO” (photo credit: “Amber")

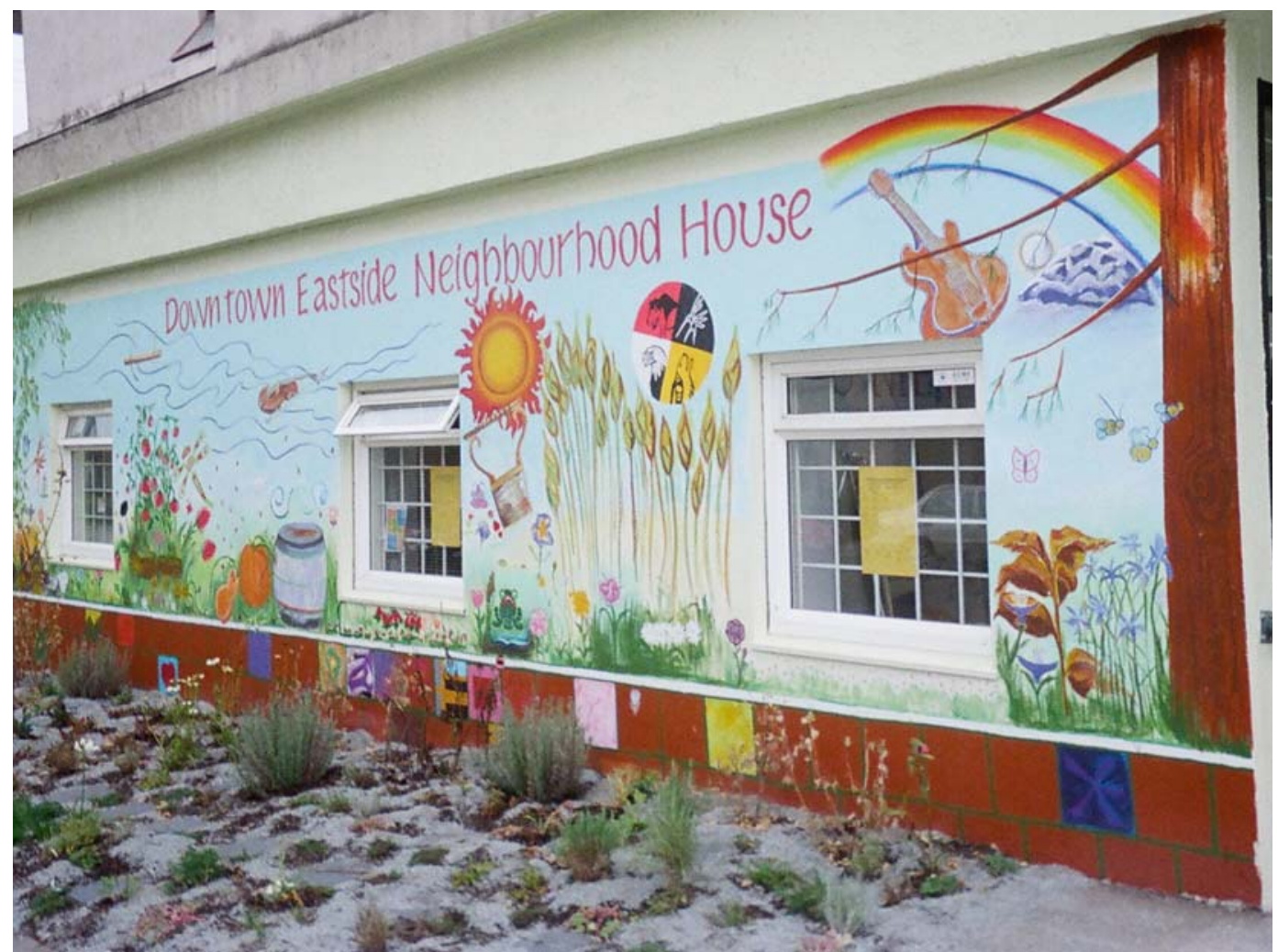

Fig. 6. "Mural" (photo credit: "Leslie") 